\title{
Genome-wide association study of brain amyloid deposition as measured by Pittsburgh Compound-B (PiB)-PET imaging
}

\author{
Qi Yan ${ }^{1,2} \cdot$ Kwangsik $\mathrm{Nho}^{3,4} \cdot$ Jorge L. Del-Aguila $\varpi^{5} \cdot$ Xingbin Wang $^{1} \cdot$ Shannon L. Risacher ${ }^{3,4} \cdot$ Kang-Hsien Fan $^{1}$. \\ Beth E. Snitz ${ }^{6,7}$. Howard J. Aizenstein ${ }^{8}$. Chester A. Mathis ${ }^{7,9}$ • Oscar L. Lopez ${ }^{6,7,8}$ • F. Yesim Demirci ${ }^{1}$. \\ Eleanor Feingold ${ }^{1} \cdot$ William E. Klunk $\mathbb{D}^{6,7,8}$. Andrew J. Saykin $\mathbb{D}^{3,4} \cdot$ for the Alzheimer's Disease Neuroimaging \\ Initiative $(\mathrm{ADNI}) \cdot$ Carlos Cruchaga ${ }^{5} \cdot$ M. Ilyas Kamboh ${ }^{1,7,8}$
}

Received: 1 December 2017 / Accepted: 31 July 2018 / Published online: 25 October 2018

(c) The Author(s) 2018. This article is published with open access

\begin{abstract}
Deposition of amyloid plaques in the brain is one of the two main pathological hallmarks of Alzheimer's disease (AD). Amyloid positron emission tomography (PET) is a neuroimaging tool that selectively detects in vivo amyloid deposition in the brain and is a reliable endophenotype for $\mathrm{AD}$ that complements cerebrospinal fluid biomarkers with regional information. We measured in vivo amyloid deposition in the brains of 1000 subjects from three collaborative AD centers and ADNI using ${ }^{11}$ C-labeled Pittsburgh Compound-B (PiB)-PET imaging followed by meta-analysis of genome-wide association studies, first to our knowledge for PiB-PET, to identify novel genetic loci for this endophenotype. The APOE region showed the most significant association where several SNPs surpassed the genome-wide significant threshold, with $A P O E^{*} 4$ being most significant $(P$-meta $=9.09 \mathrm{E}-30 ; \beta=0.18)$. Interestingly, after conditioning on $A P O E * 4,14$ SNPs remained significant at $P<0.05$ in the $A P O E$ region that were not in linkage disequilibrium with $A P O E^{*} 4$. Outside the $A P O E$ region, the metaanalysis revealed 15 non- $A P O E$ loci with $P<1 \mathrm{E}-05$ on nine chromosomes, with two most significant SNPs on chromosomes $8(P$-meta $=4.87 \mathrm{E}-07)$ and $3(P$-meta $=9.69 \mathrm{E}-07)$. Functional analyses of these SNPs indicate their potential relevance with AD pathogenesis. Top 15 non-APOE SNPs along with $A P O E^{*} 4$ explained $25-35 \%$ of the amyloid variance in different datasets, of which 14-17\% was explained by $A P O E^{*} 4$ alone. In conclusion, we have identified novel signals in $A P O E$ and non- $A P O E$ regions that affect amyloid deposition in the brain. Our data also highlights the presence of yet to be discovered variants that may be responsible for the unexplained genetic variance of amyloid deposition.
\end{abstract}

Electronic supplementary material The online version of this article (https://doi.org/10.1038/s41380-018-0246-7) contains supplementary material, which is available to authorized users.

\section{Ilyas Kamboh}

kamboh@pitt.edu

1 Department of Human Genetics, University of Pittsburgh, Pittsburgh, PA, USA

2 Department of Pediatrics, Children's Hospital of Pittsburgh of UPMC, University of Pittsburgh, Pittsburgh, PA, USA

3 Department of Radiology and Imaging Sciences, Indiana University School of Medicine, Indianapolis, IN, USA

4 Indiana Alzheimer Disease Center, Indiana University School of Medicine, Indianapolis, IN, USA

\section{Introduction}

Genomic efforts mainly through large-scale genome-wide association studies (GWAS), as part of the Alzheimer's Disease Genetics Consortium (ADGC) [1] and the International Genomics of Alzheimer's Project (IGAP) [2], have

5 Department of Psychiatry, Washington University School of Medicine, St. Louis, MO, USA

6 Department of Neurology, University of Pittsburgh, Pittsburgh, PA, USA

7 Alzheimer Disease Research Center, University of Pittsburgh, Pittsburgh, PA, USA

8 Department of Psychiatry, University of Pittsburgh, Pittsburgh, PA, USA

9 Department of Radiology, University of Pittsburgh, Pittsburgh, PA, USA 
identified over 20 genes/loci for late-onset Alzheimer's disease (AD). However, known common $\mathrm{AD}$ variants account for only $\sim 30 \%$ of the $\mathrm{AD}$ genetic variance [3], and they also do not provide definitive information about the underlying disease mechanisms. Genetic studies focusing on AD-related quantitative phenotypes/endophenotypes may help to identify additional AD-related genes. One such AD-related phenotype is deposition of amyloid-beta $(A \beta)$ in the brain, which is one of the two main pathologic hallmarks of $\mathrm{AD}$; the other being the formation of tau deposits in the form of neurofibrillary tangles, neuropil threads, and dystrophic neurites (tau pathology) in the brain [4]. According to the current model for sporadic $A D, A \beta$ pathology occurs independently of tau pathology, is detectable earlier, and is believed to accelerate neocortical tau pathology and neurodegeneration [5]. Recent longitudinal studies on cognitively normal subjects also confirm that amyloidosis is an early process in $\mathrm{AD}[6,7]$. The in vivo detection of $\mathrm{A} \beta$ deposition in the brain, as measured by positron emission tomography (PET) scanning with ${ }^{11} \mathrm{C}$ labeled Pittsburgh Compound-B (PiB) and the increased retention of $\mathrm{PiB}$ observed in the brains of $\mathrm{AD}$ patients compared with cognitively normal controls, was first reported by Klunk and colleagues [8, 9] and since has been confirmed in many studies [10]. There is a high correlation between amyloid PET imaging and neuritic plaque frequency as confirmed by autopsy studies [11-13]. Multiple studies have shown that amyloid PET has a high value for the clinical diagnosis of $\mathrm{AD}$ and in clinical trials aiming to reduce brain $\mathrm{A} \beta$ burden [14].

There is a well-established association of $A P O E$ variants with risk $[1,2]$ and age-at-onset $[15,16]$ of AD. Likewise, $A P O E$ genetic variation is also strongly associated with $\mathrm{A} \beta$ deposition in the brain as measured by PiB retention [1719], indicating a genetic basis of $A \beta$ deposition in the brain. Here, we used PiB-PET as an endophenotype to identify novel genetic loci for AD pathology using meta-analysis of three GWAS, the first to our knowledge, using the largest sample with the PiB-PET imaging from three different centers and the Alzheimer's Disease Neuroimaging Initiative (ADNI).

\section{Materials and methods}

\section{Sample description}

All subjects with PiB-PET data were European-Americans and derived from three sites: University of Pittsburgh (PITT), Washington University (WU), and Indiana University (IU) combined with the initial phase of the multicenter ADNI PiB-PET add-on study (here they are referred to as ADNI/IU). All subjects provided informed consent, and all studies were approved by their local Institutional Review Boards. The summary statistics of these samples are included in Supplementary Table S1 and their description is given Supplementary Text.

\section{Amyloid-PET data}

Detailed methods for acquisition and processing of PiBPET scans are described in previous reports for the PITT [17, 18], WU [19], ADNI [20-22], and IU [23] studies. PiB retention was measured in four cortical regions of the brain, including medial frontal cortex (MFC; anterior cingulate/ gyrus rectus), lateral frontal cortex (LFC), precuneus cortex (PRC), and parietal cortex (PAR) and expressed as a ratio to the cerebellum. In the GWAS meta-analysis, the PiB retention values from these four cortical regions were averaged in each subject to calculate a mean global score (GBL4) as the quantitative endophenotype. PiB retention was expressed as standardized uptake volume ratio (SUVR) in the PITT and ADNI/IU data [23, 24] and as binding potential (BP) in the WU data [25]. BP is approximately equal to SUVR-1. Because of this inconsistency in the PiB measurement methods, the GWAS data were analyzed via $P$-value-based meta-analysis as described below.

\section{Genotyping, imputation, and quality control}

The genotyping platforms used for each study sample are listed in Supplementary Table S1. Imputation of nongenotyped single-nucleotide polymorphisms (SNPs) was performed with IMPUTE2 [26] using the 1000 Genomes Project [27] Phase III (May 2013 release) data as the reference panel for PITT and Phase I (November 2010 release) data for WU and ADNI/IU datasets. Full description of these procedures is given in Supplementary Text.

\section{Meta-analysis}

METAL [28] software was used to perform meta-analysis on three GWAS, using the mean PiB-PET GBL4 value. METAL performs a $P$-value-based meta-analysis, which is appropriate when the effects being estimated are different in different cohorts. It does, however, account for differences in sample size between cohorts and for the direction of effects. The summary effect size was calculated by averaging the study-specific effect sizes, with weights reflecting the standard errors from the study-specific effect sizes.

\section{Functional analyses}

To evaluate the biological significance of PiB-associated signals, we conducted five different analyses: differential gene expression in $\mathrm{AD}$ versus non- $\mathrm{AD}$ in relevant tissues, 




(A) PiB (SUVR)

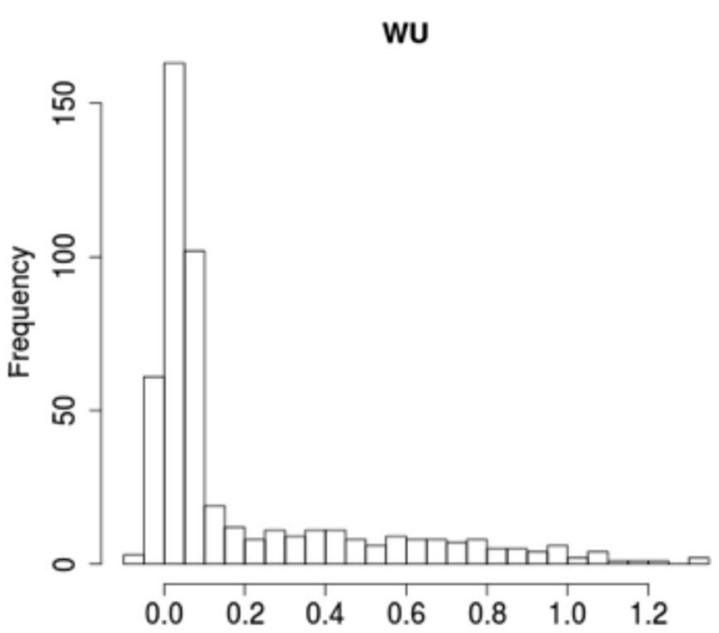

(B) PiB (PB)

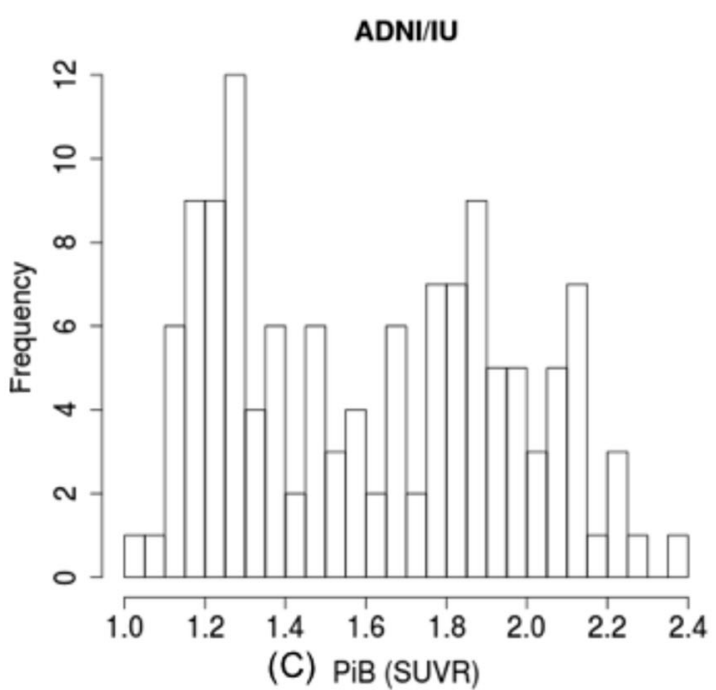

Fig. 1 Distribution of PiB retention in the University of Pittsburgh (PITT) (a), Washington University (WU) (b), and the Alzheimer's disease Neuroimaging Initiative (ADNI) and the Indiana Memory and Aging Study (ADNI/IU) (c) samples. SUVR standardized uptake volume ratio, BP binding potential brain gene expression, expression quantitative trait loci (eQTL) analyses, and summary-data-based Mendelian randomization (SMR) analyses to test for pleiotropic association between gene expression and $\mathrm{PiB}$, and pathway analyses. Detailed description of these analyses is given in Supplementary Text.

\section{Results}

\section{Amyloid PET data characteristics}

The characteristics of participants in each of the three datasets included in the meta-analysis are shown in Supplementary Table S1. The WU sample was younger with less male participants. The distribution of mean global PiB retention is shown in Fig. 1.

\section{GWAS analysis}

Quantile-quantile (QQ) plots and lambda values for the meta-analysis showed that neither the results from each of the three component studies nor the combined results from meta-analysis were inflated in their test statistics (Fig. 2a). Meta-analysis revealed 27 genome-wide significant SNPs $(P<5 \mathrm{E}-08)$ in a four-gene region on chromosome 19: PVRL2-TOMM40-APOE-APOC1(Fig. 2b, and Supplementary Table S2). As expected, $A P O E^{*} 4 / \mathrm{rs} 429358$ showed the most significant association with the average global $\mathrm{PiB}$ retention $(P$-meta $=9.09 \mathrm{E}-30 ; \beta=0.18$; Fig. 3, Supplementary Figure S1).

Outside of the $A P O E$ region, no genome-wide significant signal was observed. However, the meta-analysis revealed 15 non-APOE loci with $P<1 \mathrm{E}-05$ on chromosomes $8,3,15$, $4,21,13,2,12$, and 1 (Table 1). Most of these loci show quite consistent results across all datasets. The regional plots of these 15 non-APOE loci are shown in Supplementary Figures S2.1-S2.15. The most significant SNP outside the $A P O E$ region is intergenically located between $A D C Y 8$ and EFR3A on chromosome 8 (rs13260032; $P=4.87 \mathrm{E}-07$, Supplementary Figure S2.1). The next most significant SNP is also intergenically located between $R A P 2 B$ and $C 3$ orf79 on chromosome 3 (rs4680057; $P=9.69 \mathrm{E}-07$, Supplementary Figure S2.2). Chromosome 3 also harbors two additional signals: one in ncRNA (LINC00971/rs9831119; $P=2.98$ E-06, Supplementary Figure S2.6) and another near MAGEF1/ rs11923588 ( $P=5.66 \mathrm{E}-06$, Figure S2.9). The third most significant SNP is located in the DAPK2 gene on chromosome 15 (rs12908891; $P=1.39 \mathrm{E}-06$, Supplementary Figure S2.3). We also analyzed the data after adjusting for the effect of $A P O E^{*} 4 / \mathrm{rs} 429358$ in these non- $A P O E$ regions, which showed a slight attenuation of the association strengths (Table 1). 
a

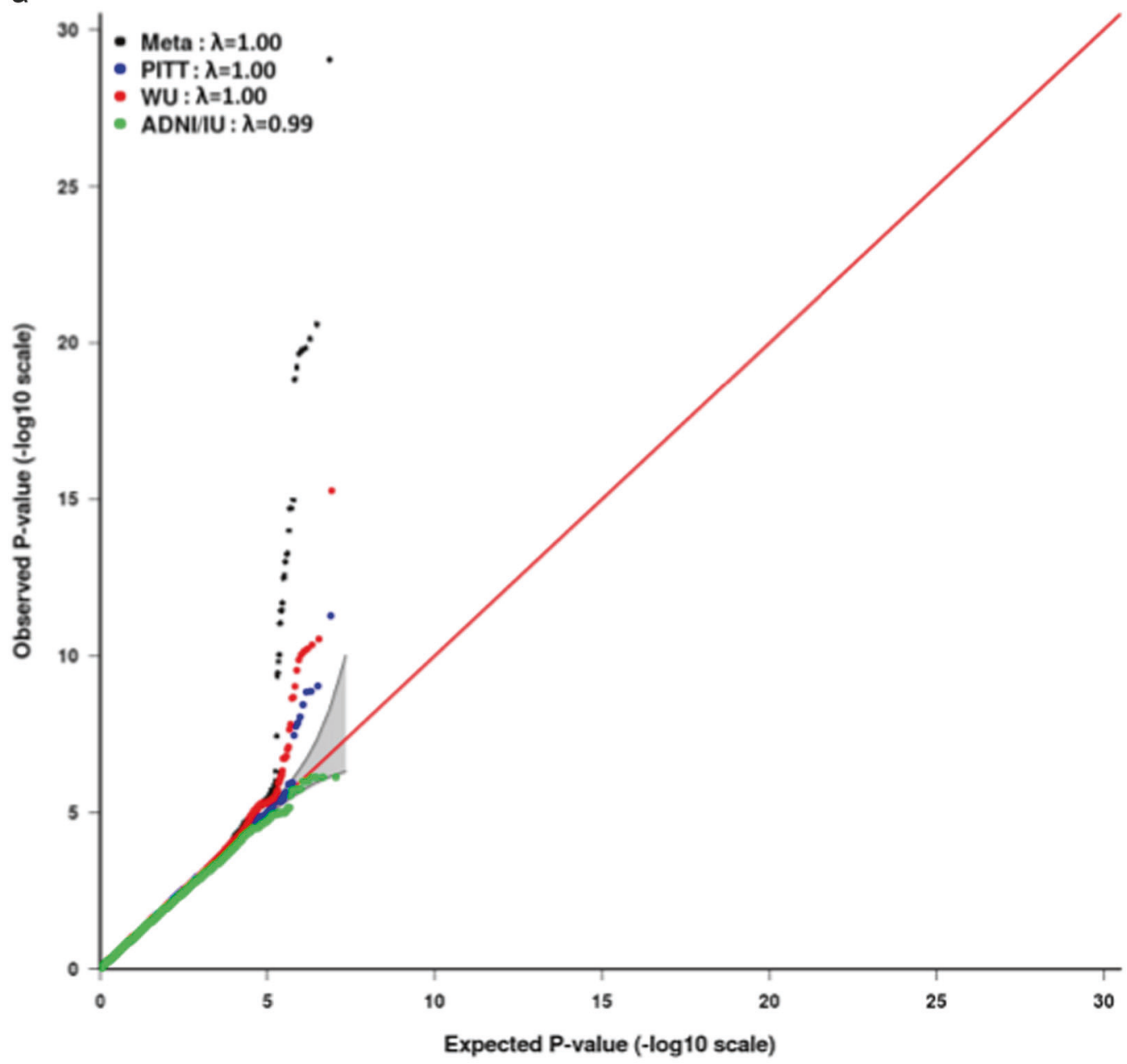

b

Meta analysis

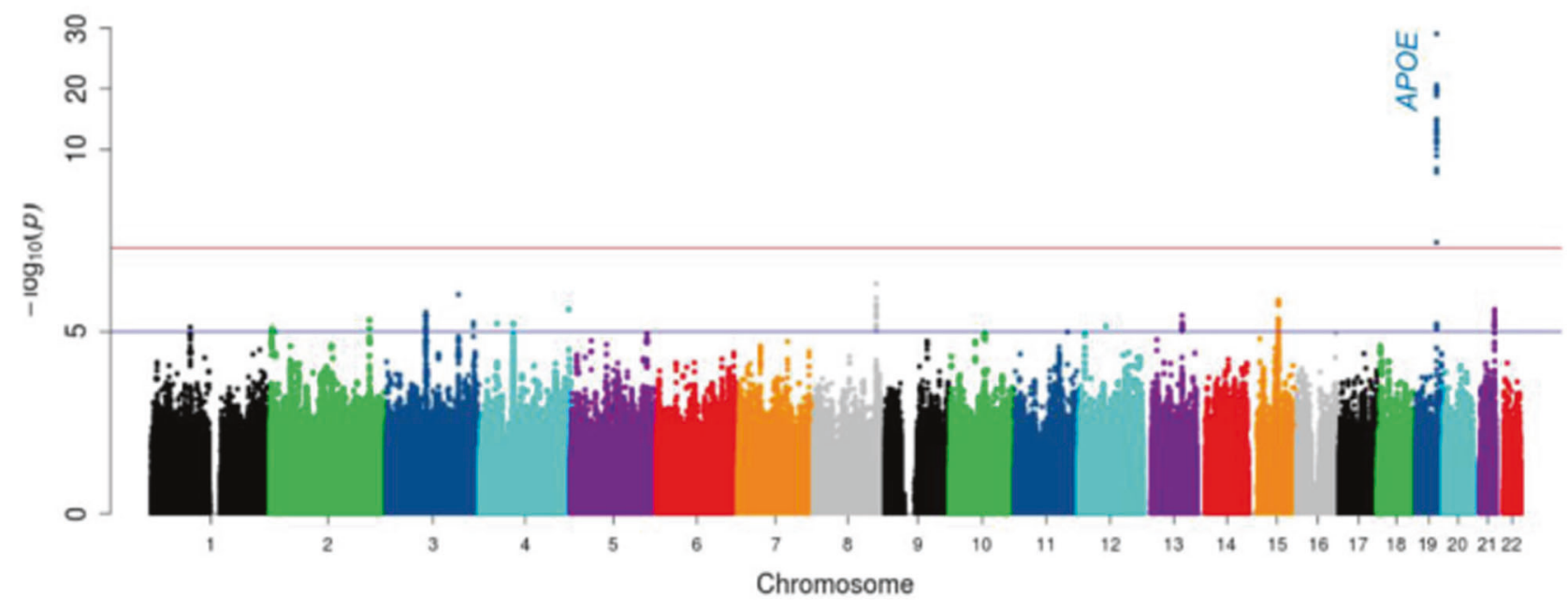

Fig. 2 a Quantile-quantile plot for the individual GWAS results in the University of Pittsburgh (PITT), Washington University (WU), and the Alzheimer's disease Neuroimaging Initiative (ADNI) and the Indiana Memory and Aging Study (ADNI/IU) datasets and in the meta- analysis. $\lambda$ is the genomic control value. $\mathbf{b}$ Manhattan plot showing the $P$-values in the meta-analysis. The blue line represents the suggestive significance line $(P<\mathrm{E}-05)$. The red line represents the significance threshold $(P<5 \mathrm{E}-08)$ 


\section{APOE region}

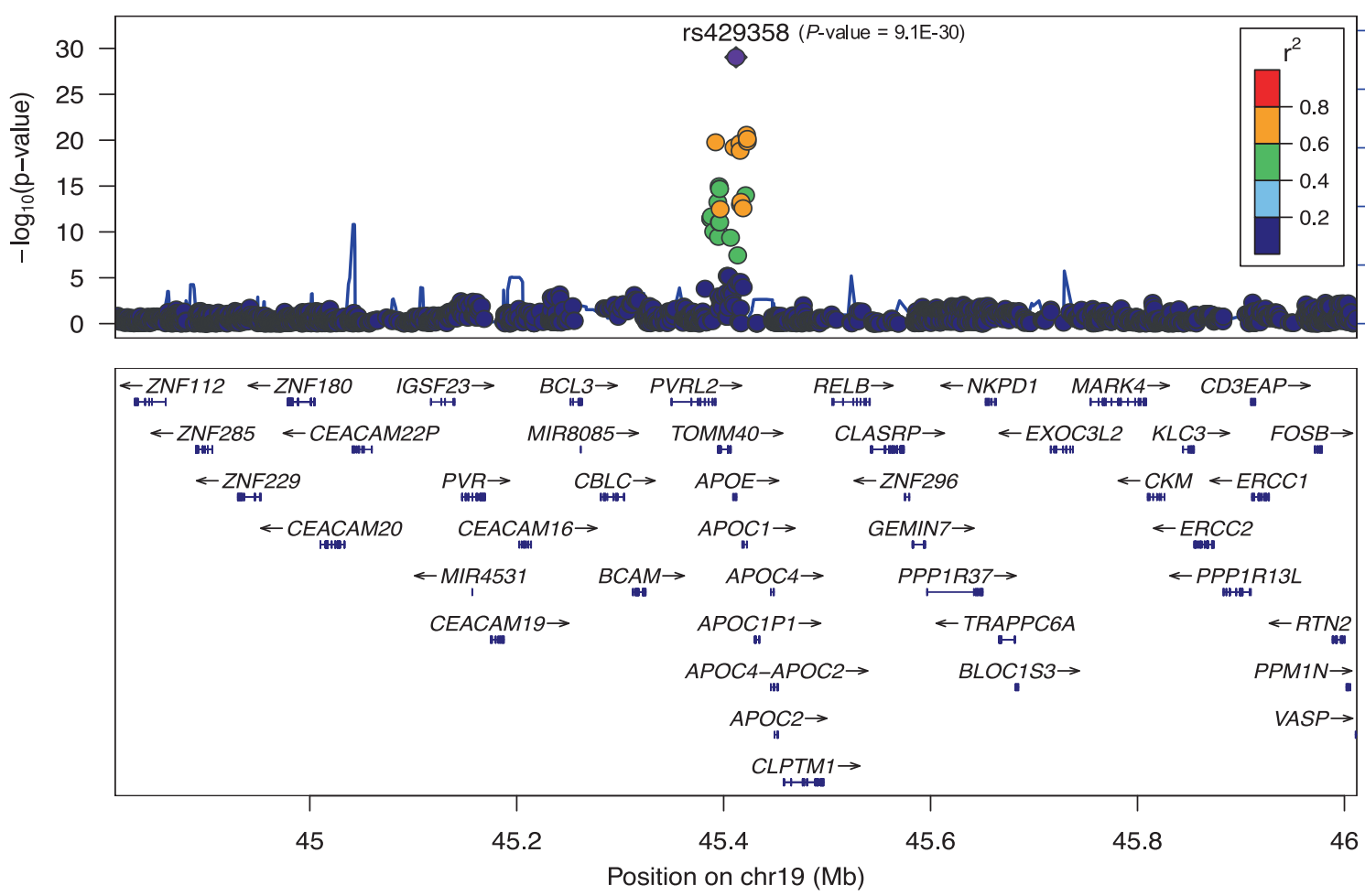

Fig. 3 Regional plot of the $A P O E$ region on chromosome 19 in the meta-analysis. The relative location of genes and the direction of transcription are shown in the lower portion of the figure, and the chromosomal position is shown on the $x$-axis. The light blue line shows the recombination rate across the region (right $y$-axis) and the

\section{Conditional analysis in the $A P O E$ region}

In order to check if there were independent SNPs associated with the PiB retention in the $A P O E$ region, we performed conditional analysis by adjusting for the top SNP $\left(A P O E^{*} 4\right.$ / rs429358). A total of 14 SNPs remained significant at $P<0.05$ (Table 2), including three SNPs that showed genome-wide significance before adjusting for $A P O E^{*} 4$ (rs75627662, rs483082, and rs438811; Supplementary Table S2). Supplementary Figure S3 shows LD structure of these 14 SNPs along with $A P O E^{*} 4 / \mathrm{rs} 429358$ and $A P O E^{*} 2 /$ rs7412 SNPs. $A P O E^{*} 4$ and $A P O E^{*} 2$ have essentially no LD with nine of the 14 SNPs that are located in the PVRL2 gene (SNPs 1-9 in Supplementary Figure S3). One SNP located in the APOE/APOCl intergenic region (rs59325138) has only very weak correlation with $A P O E^{*} 4\left(R^{2}=0.15\right)$ and $A P O E^{*} 2\left(R^{2}=0.03\right)$, while three SNPs located downstream of $A P O E$ and $A P O E / A P O C 1$ intergenic region have weak to moderate LD with $A P O E^{*} 4\left(R^{2}=0.42,0.64,0.65\right.$ for rs75627662, rs483082, and rs438811, respectively).

The most significant SNP in meta-conditional analysis was $A P O E^{*} 2 /$ rs $7412(P$-meta $=3.69 \mathrm{E}-03 ; \beta=-0.06$; Table 2$)$, left $y$-axis shows the significance of the associations. The purple diamond shows the $P$-value for rs 429358 that is the most significant SNP in the meta-analysis. The circles show the $P$-values for all other SNPs and are color coded according to the level of LD with rs429358 in the 1000 Genome Project EUR population

though it was not genome-wide significant before adjusting for $A P O E^{*} 4 \quad(P$-meta $=6.57 \mathrm{E}-05 ; \beta=-0.09)$. A similar strength of association was seen with an intronic PVRL2/ rs3852859 SNP after adjusting for $A P O E^{*} 4(P$-meta $=8.8 \mathrm{E}$ $03 ; \beta=0.06$; Table 2) that was in $\mathrm{LD}$ with three additional SNPs (SNPs 1, 7, and 9 in Supplementary Figure S3). Three additional apparently independent associations were seen with rs4803767 $(P$-meta $=2.06 \mathrm{E}-02 ; \beta=0.05$ Table 2$)$ that was in LD with four additional SNPs (SNPs $2-5$ in Supplementary Figure S3), rs75627662 $(P$-meta $=1.50 \mathrm{E}-02 ; \beta=-0.03$; Table 2) that was in LD with two additional SNPs (SNPs 13, 15 in Supplementary Figure S3), and rs59325138 ( $P$-meta $=$ $3.10 \mathrm{E}-02 ; \beta=0.03$; Table 2$)$ that has very weak correlation with all other SNPs $\left(R^{2}=0.01-0.24\right)$.

\section{Association of known AD risk loci with amyloid burden and association of amyloid loci with AD risk}

We examined the top IGAP genome-wide significant SNPs (Supplementary Table S3.1) and the associated gene regions (Supplementary Table S3.2) in relation to amyloid burden and found only some nominally significant SNPs. Likewise, 


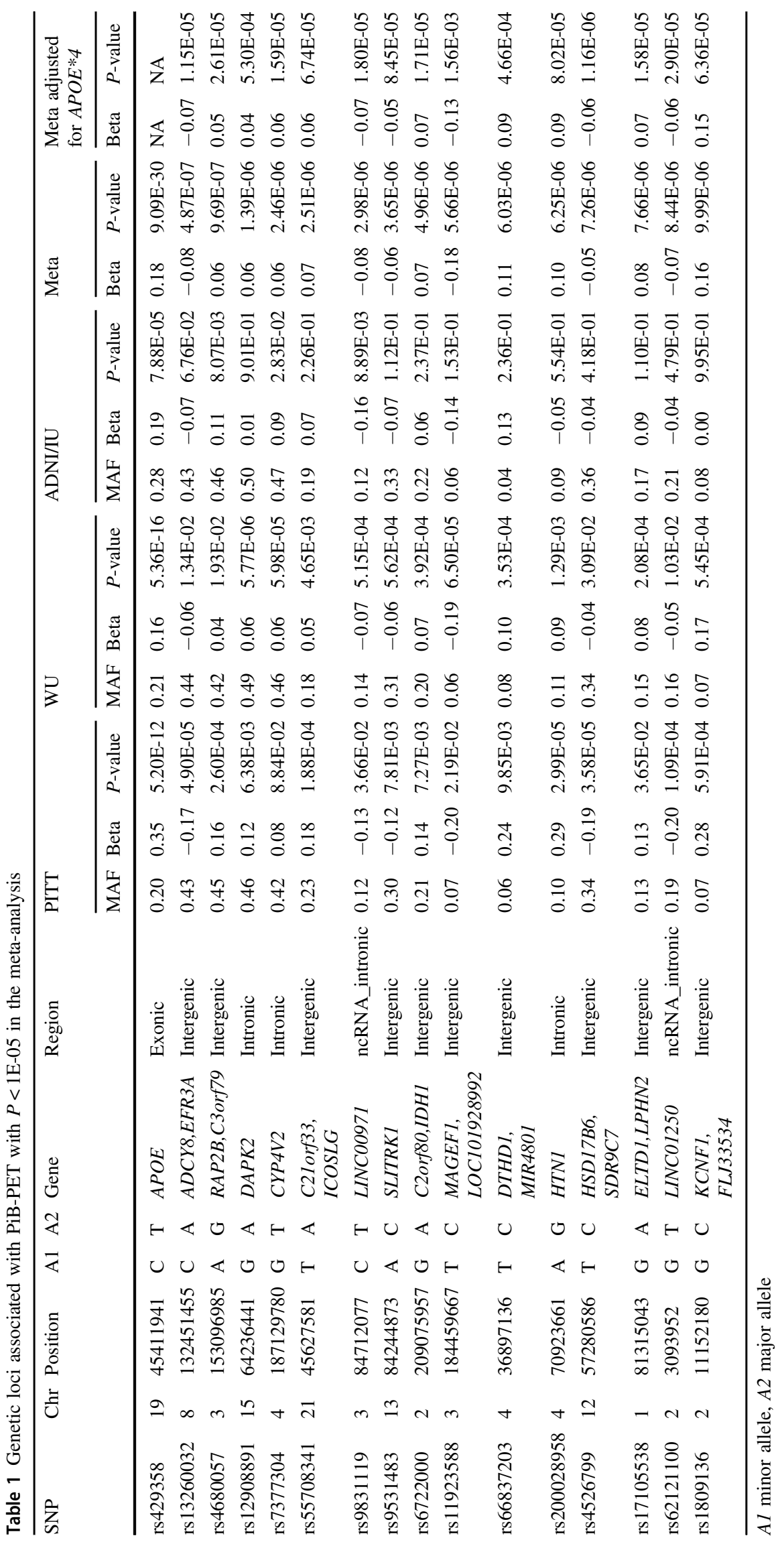




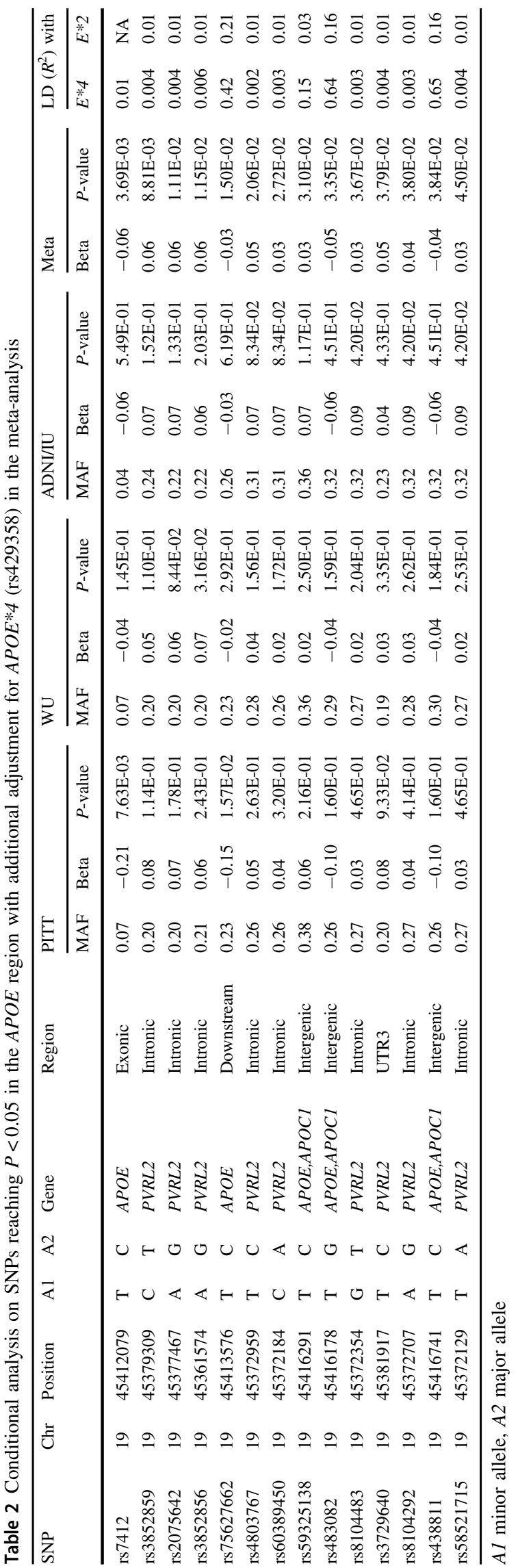

we examined the suggestive non- $A P O E$ amyloid loci in our PITT-ADRC case-control sample of $>2200$ subjects [29] and found association of two top amyloid-associated SNPs with AD risk (Supplementary Table S4.1). When we examined additional $A \beta$-associated SNPs in each region with AD risk, we found multiple associations with $P<0.05$ (Supplementary Table S4.2), indicating that our suggestive $\mathrm{A} \beta$-associated loci are also associated with $\mathrm{AD}$ risk (see Supplementary Text for more details).

\section{Estimation of amyloid-PET variance by $A P O E$ and non-APOE loci}

The genetic variance was estimated based on the R-square calculated from a linear regression model regressing global $\mathrm{PiB}$ retention on six independent APOE SNPs (rs429358, rs7412, rs3852859, rs4803767, rs75627662, and rs59325138), as described above, and 15 non-APOE SNPs given in Table 1. The contribution of six APOE SNPs to the variance of global $\mathrm{PiB}$ retention was $28.0,17.3$, and $17.12 \%$ in the PITT, WU, and ADNI/IU datasets, respectively; APOE*4/rs429358 alone explained 17.5, 16.5, and 13.9\%, respectively. The top 15 non-APOE SNPs explained 22.6, 21.6, and $21.7 \%$ of the amyloid variance in the PITT, WU, and ADNI/IU datasets, respectively. The consistency of these estimates across the different datasets gives confidence that the difference in measurement of $\mathrm{PiB}$ across the datasets does not affect the bottom-line results.

\section{Functional analyses}

We performed five analyses (Methods section) to evaluate the biological significance of PiB-implicated signals/genes. We considered all genes within $\pm 500 \mathrm{~kb}$ of the top variant in each locus from Table 1 plus any eQTL-controlled genes outside the $\pm 500 \mathrm{~kb}$ boundary as target genes (Fig. 3, Supplementary Figures S2.1-S2.15) and selected a total of 257 genes.

Of 257 target genes, we found 20 upregulated and 25 downregulated genes that were differentially expressed in the same direction in two or more AD studies and no opposite directions were reported (Fig. 4 and Supplementary Table S6 marked in green color). Brain RNA-seq data reveals that many of these differentially expressed candidate genes are expressed in AD-relevant cell types (Fig. 4 and Supplementary Table S6 marked in yellow color).

For eQTL analyses, we identified SNPs in LD $\left(R^{2} \geq 0.5\right)$ with the top SNP for each locus in Table 1. For these SNPs, there were $c i s$-acting eQTLs (eQTL $P<0.05$ ) for 151 of the 257 target genes in various brain tissues and 36 genes in whole blood available in GTEx. Supplementary Table S5 gives the eQTL results for each top SNP in 15 non-APOE loci, and the detailed results of LD SNPs $\left(R^{2} \geq 0.80\right)$ with 
top SNPs are given in Supplementary Table S7. With the exception of SLITRK1/rs9831119, the other 14 top SNPs were eQTLs in different brain regions; 11 of them were eQTL in anterior cingulate cortex/frontal cortex/cortex where $\mathrm{PiB}$ intake is highest [30], indicating their role in affecting amyloid deposition in the brain.

For SMR analyses, only the gene/variant pairs identified in the cis-eQTL analyses were considered. For these gene/ variant pairs, 99 genes in any brain tissue and 19 in whole

\begin{tabular}{|c|c|c|c|c|c|c|c|c|c|c|}
\hline Locus & Target gene & Chr & $\begin{array}{c}\text { Expression } \\
\text { in brain } \\
\text { (Barres) }\end{array}$ & $\begin{array}{c}\text { Differential } \\
\text { expression } \\
\text { in } A D\end{array}$ & $\begin{array}{c}\text { eQTL } \\
\text { in } \\
\text { blood }\end{array}$ & $\begin{array}{c}\text { SMR } \\
\text { in } \\
\text { blood }\end{array}$ & $\begin{array}{l}\text { eQTL in } \\
\text { any brain } \\
\text { tissues }\end{array}$ & $\begin{array}{l}\text { SMR in } \\
\text { any brain } \\
\text { tissues }\end{array}$ & Pathway & $\begin{array}{c}\text { Non-APOE } \\
\text { locus } \\
\text { pathway }\end{array}$ \\
\hline \multirow{22}{*}{$A P O E$} & APOC1 & 19 & & & & & & & & \\
\hline & $A P O C 2$ & 19 & & & & & & & & \\
\hline & $A P O E$ & 19 & & & & & & & & \\
\hline & $B C A M$ & 19 & & & & & & & & \\
\hline & $B C L 3$ & 19 & & & & & & & & \\
\hline & BLOC1S3 & 19 & & & & & & & & \\
\hline & CD3EAP & 19 & & & & & & & & \\
\hline & CEACAM19 & 19 & & & & & & & & \\
\hline & CKM & 19 & & & & & & & & \\
\hline & CLASRP & 19 & & & & & & & & \\
\hline & CLPTM1 & 19 & & & & & & & & \\
\hline & $E R C C 1$ & 19 & & & & & & & & \\
\hline & $E R C C 2$ & 19 & & & & & & & & \\
\hline & EXOC3L2 & 19 & & & & & & & & \\
\hline & GEMIN7 & 19 & & & & & & & & \\
\hline & $K L C 3$ & 19 & & & & & & & & \\
\hline & NKPD1 & 19 & & & & & & & & \\
\hline & PPP1R13L & 19 & & & & & & & & \\
\hline & PVRL2 & 19 & & & & & & & & \\
\hline & TOMM40 & 19 & & & & & & & & \\
\hline & TRAPPC6A & 19 & & & & & & & & \\
\hline & ZNF180 & 19 & & & & & & & & \\
\hline \multirow[t]{2}{*}{$A D C Y 8, E F R 3 A$} & $A D C Y 8$ & 8 & & & & & & & & \\
\hline & EFR3A & 8 & & & & & & & & \\
\hline \multirow[t]{2}{*}{ RAP2B, C3orf79 } & $R A P 2 B$ & 3 & & & & & & & & \\
\hline & DHX36 & 3 & & & & & & & & \\
\hline \multirow[t]{16}{*}{$D A P K 2$} & CSNK1G1 & 15 & & & & & & & & \\
\hline & DAPK2 & 15 & & & & & & & & \\
\hline & FBXL22 & 15 & & & & & & & & \\
\hline & HERC1 & 15 & & & & & & & & \\
\hline & KIAA0101 & 15 & & & & & & & & \\
\hline & PPIB & 15 & & & & & & & & \\
\hline & SNX1 & 15 & & & & & & & & \\
\hline & SNX22 & 15 & & & & & & & & \\
\hline & TRIP4 & 15 & & & & & & & & \\
\hline & USP3 & 15 & & & & & & & & \\
\hline & LACTB & 15 & & & & & & & & \\
\hline & RPS27L & 15 & & & & & & & & \\
\hline & $R A B 8 B$ & 15 & & & & & & & & \\
\hline & ZNF609 & 15 & & & & & & & & \\
\hline & PLEKHO2 & 15 & & & & & & & & \\
\hline & $A N K D D 1 A$ & 15 & & & & & & & & \\
\hline \multirow[t]{7}{*}{ CYP4V2 } & CYP4V2 & 4 & & & & & & & & \\
\hline & FAM149A & 4 & & & & & & & & \\
\hline & FAT1 & 4 & & & & & & & & \\
\hline & $K L K B 1$ & 4 & & & & & & & & \\
\hline & MTNR1A & 4 & & & & & & & & \\
\hline & SORBS2 & 4 & & & & & & & & \\
\hline & TLR3 & 4 & & & & & & & & \\
\hline \multirow{8}{*}{$\begin{array}{l}\text { C21orf33, } \\
\text { ICOSLG }\end{array}$} & CSTB & 21 & & & & & & & & \\
\hline & ICOSLG & 21 & & & & & & & & \\
\hline & PFKL & 21 & & & & & & & & \\
\hline & $R R P 1$ & 21 & & & & & & & & \\
\hline & TRAPPC10 & 21 & & & & & & & & \\
\hline & HSF2BP & 21 & & & & & & & & \\
\hline & $R R P 1 B$ & 21 & & & & & & & & \\
\hline & UBE2G2 & 21 & & & & & & & & \\
\hline LINC00971 & CADM2 & 3 & & & & & & & & \\
\hline SLITRK1 & SLITRK1 & 13 & & & & & & & & \\
\hline \multirow[t]{7}{*}{ C2orf80, IDH1 } & C2orf80 & 2 & & & & & & & & \\
\hline & CRYGD & 2 & & & & & & & & \\
\hline & FZD5 & 2 & & & & & & & & \\
\hline & $I D H 1$ & 2 & & & & & & & & \\
\hline & PIKFYVE & 2 & & & & & & & & \\
\hline & PLEKHM3 & 2 & & & & & & & & \\
\hline & PTH2R & 2 & & & & & & & & \\
\hline
\end{tabular}




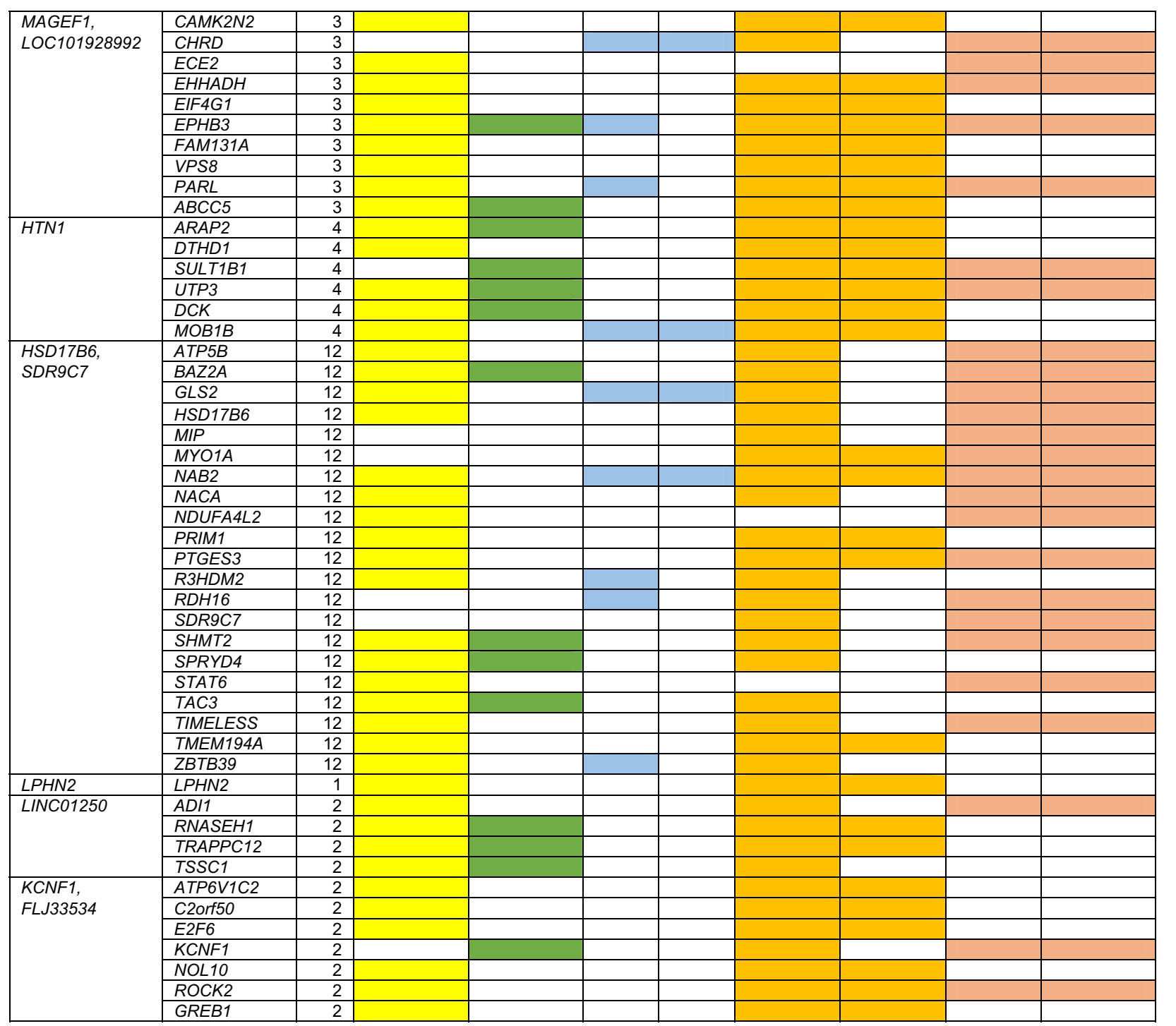

Fig. 4 The functional analysis results for target genes. Out of 257 target genes, only genes meeting at least three functional criteria are listed. The criteria include: (1) differential expression in at least two Alzheimer disease studies that up- or downregulated consistently in different studies; (2) expression in the brain cells (Barres website); (3) having $c i s$-eQTL effects in any brain tissues using GTEx database $(P$
$<0.05$ ); 4) mediating genetic effects on PiB (SMR analysis with $P<$ $0.05)$ in any brain tissues; (5) having cis-eQTL effects in whole blood $(P<0.05)$; $(6)$ mediating genetic effects on PiB (SMR analysis with $P$ $<0.05$ ) in whole blood; and (7) included in nominally significant pathways. The detailed results are summarized in Supplementary Table S6 blood were shown to mediate genetic effects on PiB by cisregulating gene expression (SMR $P<0.05$; Fig. 4, Supplementary Table S6).

We conducted pathway analyses (MAGMA [31]) using four gene set resources, including and excluding target genes in the $A P O E$ region, and detected nine genomewide significant pathways: NDK dynamin pathway, $F D R$ $=4.6 \mathrm{E}-04 ;$ synaptic vesicle recycling, $F D R=3.5 \mathrm{E}-07$; synaptic vesicle endocytosis, $F D R=3.1 \mathrm{E}-04$; protein depolymerization, $F D R=3.1 \mathrm{E}-04$; inositol tetrakisphosphate phosphatase activity, $F D R=5.7 \mathrm{E}-03$; positive regulation of vacuole organization, $F D=5.7 \mathrm{E}-03$; inositol trisphosphate phosphatase activity, $F D R=0.033$; regulation of clathrin-mediated endocytosis, $F D R=$ 0.038; and clathrin-mediated endocytosis, $F D R=0.043$. Although none of the 257 target genes, including APOE, are included in these nine genome-wide significant pathways, 71 target genes are included in the nominally significant pathways, and 46 target genes are included in the non- $A P O E$ region-related nominally significant pathways $(P<0.05$. Fig. 4 and Supplementary Table S6 marked in pink color). 


\section{Discussion}

In this investigation, we have used the largest PiB-PET imaging data $(n=\sim 1000)$, available from multiple collaborative centers, as an endophenotype to identify novel genetic loci for AD pathology using the GWAS metaanalysis approach, the first to our knowledge for PiB-PET.

The APOE region showed the most significant association where several SNPs surpassed the genome-wide significant threshold $(P<5 \mathrm{E}-08)$, with $A P O E^{*} 4$ as the top hit that was associated with higher $\mathrm{PiB}$ retention in the brain $(P$-meta $=9.09 \mathrm{E}-30 ; \quad \beta=0.18) . \quad A P O E^{*} 2, \quad$ a protective genetic factor against $\mathrm{AD}$, was associated with lower $\mathrm{PiB}$ retention, albeit, not genome-wide significant $(P$-meta $=$ 6.57E-05; $\beta=-0.09$ ). This observation is consistent with earlier reports of the association of the $A P O E^{*} 2 / 3 / 4$ polymorphism with $A \beta$ deposition in the brain as measured by PiB-PET [17-19] or florbetapir-PET [32]. Likewise, a GWAS of cerebrospinal fluid (CSF) $\mathrm{A} \beta$ has identified a genome-wide significant SNP that was a proxy for $A P O E^{* 4}$ [33]. Numerous prior studies have investigated the role of the $A P O E^{*} 2 / 3 / 4$ polymorphism on $A \beta$ production, aggregation, and clearance in the brain [34], but recent studies provide solid mechanistic clues into the role of $A P O E$ genetic variation in affecting APP transcription and $A \beta$ production [35], and seeding of amyloid pathology [36]. In addition to the $A P O E^{*} 2 / 3 / 4$ association, conditional analysis on $A P O E^{*} 4$ identified 14 independent signals in the $A P O E$ region that also affect brain amyloidosis. Nine of 14 SNPs had essentially no LD with $A P O E^{* 4}$ and $A P O E^{* 2}$, and the remaining five showed moderate to weak $\mathrm{LD}$ with $A P O E^{*} 4$. Thus, our meta-analysis indicates the presence of additional signals in the $A P O E$ region, beyond the $A P O E^{*} 4$ I rs429358 and $A P O E^{*} 2 / \mathrm{rs} 7412$ SNPs, that affect $\mathrm{A} \beta$ deposition in the brain.

Outside the $A P O E$ region, the meta-analysis revealed 15 suggestive non-APOE loci with $P<1 \mathrm{E}-05$ on nine chromosomes. Although they do not meet the established genome-wide significance criteria, their consistent and directional associations in three independent datasets (Table 1) suggest that at least some of them are likely candidate loci for brain amyloidosis process and/or AD risk and variants in these loci may have achieved the genomewide significance threshold in larger datasets. Credence to this idea was provided by our observation that most of these suggestive loci were also associated with $\mathrm{AD}$ risk when we examined the $A \beta$-associated SNPs in a published AD GWAS [29] (Supplementary Tables S4.1-S4.2). The most significant non-APOE SNP (rs13260032; $P=4.87 \mathrm{E}-07$ ) on chromosomes 8 is intergenic, and this was an eQTL for a nearby $A D C Y 8$ gene in frontal cortex, which is one of the highest PiB uptake cortical regions [30]. ADCY8 is essential to long-term potentiation and synaptic plasticity and is implicated in memory and learning [37]. Genetic variation in or around $A D C Y 8$ has shown to be associated with dissociation symptoms in subjects with post-traumatic stress disorder [37], abdominal visceral [38] and alcoholdependent depression [39]. The second top SNP (rs4680057; $P=9.69 \mathrm{E}-07$ ) resides near $C 3$ orf79 and was an eQTL for a nearby long noncoding RNA (lncRNA) gene in anterior cingulate cortex and hippocampus in the brain and for ARHGEF26 in blood. IncRNAs play a critical role in gene regulatory networks and may affect diverse biological processes and diseases [40], including $\mathrm{AD}$ where several IncRNAs have been shown to regulate A $\beta$ production/generation [41, 42]. A recent GWAS has identified $A R H G E F 26$ as a new genetic factor for coronary artery disease risk that influences the transendothelial migration of leukocytes [43]. The third top SNP (rs12908891; $P=1.39 \mathrm{E}-06)$ is located DAPK2 on chromosome 15 that belongs to a family of related serine/threonine kinases shown to be involved in multiple functions, including apoptosis, autophagy, tumor suppression, and inflammation [44]. Although the role of $D A P K 2$ in amyloidosis in unknown, another family member, $D A P K 1$, promotes the phosphorylation and amyloidogenic processing of APP [45]. The DAPK2 region contains other candidate genes, such as GSNKIGI and TRIP4. While TRIP4 is a known gene for AD [46], GSNK1G1 has been implicated in the formation of $A \beta$ [47]. The top SNP was the most significant eQTL for HERC1 gene expression in anterior cingulate cortex $\left(P \_\right.$eQTL $\left.=7.02 \mathrm{E}-05 ; P \_\mathrm{SMR}=1.94 \mathrm{E}-03\right)$. HERC1 belongs to the ubiquitin-proteasome system that plays a key role in the protein degradation pathway essential for neuronal homeostasis, synaptic development and maintenance. Mutations in HERCl have been associated with intellectual disability [48] and autism spectrum disorders [49].

To identify additional PiB-relevant candidate genes, we combined results from the brain expression, differential brain expression in $\mathrm{AD}$, eQTL/SMR in the brain, and pathway analyses. Four genes meeting all these functional criteria were identified: RPS $27 L$ in the $D A P K 2$ region, CYP4V2 and TLR3 in the CYP4V2 region, and IDH1 in the IDH1/C2orf80 region (Fig. 4, Supplementary Table S6). RPS27L is an evolutionarily conserved ribosomal protein and a physiological regulator of transcription factor p53 that is involved in genomic stability and tumor suppression [50]. p53 has also been implicated in AD progression, in part, due to its interaction with $A \beta$ in $A D$ progression [51]. p53 also interact with IDH1 in glioblastoma [52]. It seems that the involvement of RPS27L and IDH1 in the amyloidogenic process is through their effect on or interaction with $\mathrm{p} 53$. Although the role of CYP4V2 in amyloidosis is currently unclear, activated TLR3, along with some members of the toll-like receptors family, can induce $A \beta$ uptake or inflammatory response during the AD progression [53]. Further 
functional characterization of these candidate genes may help to elucidate their roles in brain amyloidosis.

A recent GWAS using CSFA $\beta 42$ as an endophenotype has identified two novel loci in addition to the $A P O E$ locus [33]. One locus is near GLISI on chromosome 1 and the other in SERPINBI on chromosome 6. The reported GLIS1/ 185031519 SNP was neither present in our genotyping array nor was it imputed. This SNP was also not in high LD with other SNPs. On the other hand, the reported SER$P I N B 1 / \mathrm{rs} 316341 \mathrm{SNP}$ was present in our data, but it was not significant $(P=0.148)$. We also examined four additional reported SERPINBI SNPs with $P<1 \mathrm{E}-05$ (rs316339, rs316337, rs392120, rsrs2293772) [33] and found one of them to be nominally significant in our data (rs392120; $P=0.033$ ).

We estimated the genetic variance of global PiB retention explained by the APOE and top 15 non-APOE SNPs with $P<1 \mathrm{E}-05$ using a linear regression model. The non$A P O E$ SNPs along with $A P O E^{*} 4$ explained $25-35 \%$ of the amyloid variance; of which $14-17 \%$ was explained by $A P O E^{*} 4$ alone. A previous study using a different amyloid tracer (florbetapir-PET) [32] found a similar contribution of $A_{P O E}^{*} 4(11 \%)$ to amyloid variance. However, a GWAS on CSF A $\beta 42$ found a smaller contribution of $A P O E^{*} 4$ (4\%) to amyloid variance [33]. This may be due to the use of different methods to estimate the amyloid variance. While the CSF study used the Genome-wide Complex Trait Analysis (GCTA) that requires $>3000$ sample size [54], the two amyloid tracer studies with smaller sample sizes used linear regression. Our data, in conjunction with previous studies, highlight the presence of yet to be discovered variants that may be responsible for the unexplained genetic variance of amyloid deposition.

As with any genome-wide study, this study has limitations. Although the present study used the largest combined sample of PiB-PET imaging data reported todate (from three different centers and ADNI), the sample size was relatively small to achieve genome-wide significance for loci with small effect sizes. We predict that at least some of our suggestive loci with $P<1 \mathrm{E}-05$ might have achieved genome-wide significance with a larger sample size, as the direction of allelic effects for all suggestive loci were consistent in all datasets. Unlike some other phenotypes where data could be obtained readily on large numbers of subjects at a relatively lowcost, this is not the case with amyloid PET. Thus, the lack of a very large PiB-PET imaging database for a genome-wide study was a significant constraint. As more PiB-PET imaging data are obtained by different centers, future collaborative studies, as done here, on larger samples may allow the identification of additional genes for brain amyloidosis.
In conclusion, this is the first GWAS on PiB-PET that has confirmed the established association of the $A P O E$ locus with in vivo brain amyloidosis. In addition to the known association, we have identified novel variants in the $A P O E$ region that affect amyloidosis. A combination of genetic and functional approaches has also led to the identification of additional putative candidate genes that warrant follow-up genetic and functional studies to confirm their role in brain amyloidosis.

Acknowledgements This study was supported by the US National Institutes of Health grants AG030653, AG041718, AG005133, AG025516, AG025204, AG044546, AG003991, AG053303, AG054936, LM012535, AG05681, G026276, and AG024904, and DOD ADNI (Department of Defense award W81XWH-12-2-0012). See full acknowledgments in Supplementary Material.

\section{Compliance with ethical standards}

Conflict of interest GE Healthcare holds a license agreement with the University of Pittsburgh based on the PiB-PET technology described in this manuscript. Drs. Klunk and Mathis are co-inventors of PiB and, as such, have a financial interest in this license agreement. The remaining authors declare that they have no conflict of interest.

Open Access This article is licensed under a Creative Commons Attribution 4.0 International License, which permits use, sharing, adaptation, distribution and reproduction in any medium or format, as long as you give appropriate credit to the original author(s) and the source, provide a link to the Creative Commons license, and indicate if changes were made. The images or other third party material in this article are included in the article's Creative Commons license, unless indicated otherwise in a credit line to the material. If material is not included in the article's Creative Commons license and your intended use is not permitted by statutory regulation or exceeds the permitted use, you will need to obtain permission directly from the copyright holder. To view a copy of this license, visit http://creativecommons. org/licenses/by/4.0/.

\section{References}

1. Naj AC, Jun G, Beecham GW, Wang LS, Vardarajan BN, Buros J, et al. Common variants at MS4A4/MS4A6E, CD2AP, CD33 and EPHA1 are associated with late-onset Alzheimer's disease. Nat Genet. 2011;43:436-41.

2. Lambert JC, Ibrahim-Verbaas CA, Harold D, Naj AC, Sims R, Bellenguez C, et al. Meta-analysis of 74,046 individuals identifies 11 new susceptibility loci for Alzheimer's disease. Nat Genet. 2013;45:1452-8.

3. Ridge PG, Hoyt KB, Boehme K, Mukherjee S, Crane PK, Haines $\mathrm{JL}$, et al. Assessment of the genetic variance of late-onset Alzheimer's disease. Neurobiol Aging. 2016;41:e213-200 e220. 200

4. Hyman BT, Phelps CH, Beach TG, Bigio EH, Cairns NJ, Carrillo $\mathrm{MC}$, et al. National Institute on Aging-Alzheimer's Association guidelines for the neuropathologic assessment of Alzheimer's disease. Alzheimers Dement. 2012;8:1-13.

5. Jack CR,Jr., Knopman DS, Jagust WJ, Petersen RC, Weiner MW, Aisen PS. et al. Tracking pathophysiological processes in 
Alzheimer's disease: an updated hypothetical model of dynamic biomarkers. Lancet Neurol. 2013;12:207-16.

6. Jack CR,Jr, Therneau TM, Wiste HJ, Weigand SD, Knopman DS, Lowe VJ. et al. Transition rates between amyloid and neurodegeneration biomarker states and to dementia: a population-based, longitudinal cohort study. Lancet Neurol. 2016;15:56-64.

7. Burnham SC, Bourgeat P, Dore V, Savage G, Brown B, Laws S, et al. Clinical and cognitive trajectories in cognitively healthy elderly individuals with suspected non-Alzheimer's disease pathophysiology (SNAP) or Alzheimer's disease pathology: a longitudinal study. Lancet Neurol. 2016;15:1044-53.

8. Klunk WE, Engler H, Nordberg A, Wang Y, Blomqvist G, Holt DP, et al. Imaging brain amyloid in Alzheimer's disease with Pittsburgh Compound-B. Ann Neurol. 2004;55:306-19.

9. Price JC, Klunk WE, Lopresti BJ, Lu X, Hoge JA, Ziolko SK, et al. Kinetic modeling of amyloid binding in humans using PET imaging and Pittsburgh Compound-B. J Cereb Blood Flow Metab. 2005;25:1528-47.

10. Jack CR Jr, Barrio JR, Kepe V. Cerebral amyloid PET imaging in Alzheimer's disease. Acta Neuropathol. 2013;126:643-57.

11. Clark CM, Pontecorvo MJ, Beach TG, Bedell BJ, Coleman RE, Doraiswamy PM, et al. Cerebral PET with florbetapir compared with neuropathology at autopsy for detection of neuritic amyloidbeta plaques: a prospective cohort study. Lancet Neurol. 2012;11:669-78.

12. Sabri O, Sabbagh MN, Seibyl J, Barthel H, Akatsu H, Ouchi Y, et al. Florbetaben PET imaging to detect amyloid beta plaques in Alzheimer's disease: phase 3 study. Alzheimers Dement. 2015;11:964-74.

13. Curtis C, Gamez JE, Singh U, Sadowsky CH, Villena T, Sabbagh $\mathrm{MN}$, et al. Phase 3 trial of flutemetamol labeled with radioactive fluorine 18 imaging and neuritic plaque density. JAMA Neurol. 2015;72:287-94

14. Blennow K, Mattsson N, Scholl M, Hansson O, Zetterberg H. Amyloid biomarkers in Alzheimer's disease. Trends Pharmacol Sci. 2015;36:297-309.

15. Kamboh MI, Barmada MM, Demirci FY, Minster RL, Carrasquillo MM, Pankratz VS, et al. Genome-wide association analysis of age-at-onset in Alzheimer's disease. Mol Psychiatry. 2012;17:1340-6.

16. Naj AC, Jun G, Reitz C, Kunkle BW, Perry W, Park YS, et al. Effects of multiple genetic loci on age at onset in late-onset Alzheimer disease: a genome-wide association study. JAMA Neurol. 2014;71:1394-404.

17. Mathis CA, Kuller LH, Klunk WE, Snitz BE, Price JC, Weissfeld LA, et al. In vivo assessment of amyloid-beta deposition in nondemented very elderly subjects. Ann Neurol. 2013;73:751-61.

18. Nebes RD, Snitz BE, Cohen AD, Aizenstein HJ, Saxton JA, Halligan EM, et al. Cognitive aging in persons with minimal amyloid-beta and white matter hyperintensities. Neuropsychologia. 2013;51:2202-9.

19. Morris JC, Roe CM, Xiong C, Fagan AM, Goate AM, Holtzman $\mathrm{DM}$, et al. APOE predicts amyloid-beta but not tau Alzheimer pathology in cognitively normal aging. Ann Neurol. 2010;67:12231.

20. Swaminathan S, Shen L, Risacher SL, Yoder KK, West JD, Kim S, et al. Amyloid pathway-based candidate gene analysis of [(11)C] PiB-PET in the Alzheimer's Disease Neuroimaging Initiative (ADNI) cohort. Brain Imaging Behav. 2012;6:1-15.

21. Saykin AJ, Shen L, Yao X, Kim S, Nho K, Risacher SL, et al. Genetic studies of quantitative MCI and AD phenotypes in ADNI: progress, opportunities, and plans. Alzheimers Dement. 2015;11:792-814.

22. Jagust WJ, Bandy D, Chen K, Foster NL, Landau SM, Mathis CA, et al. The Alzheimer's Disease Neuroimaging Initiative positron emission tomography core. Alzheimers Dement. 2010;6:221-9.
23. Deters KD, Risacher SL, Yoder KK, Oblak AL, Unverzagt FW, Murrell JR, et al. [(11)C]PiB PET in Gerstmann-StrausslerScheinker disease. Am J Nucl Med Mol Imaging. 2016;6:84-93.

24. Risacher SL, Kim S, Shen L, Nho K, Foroud T, Green RC, et al. The role of apolipoprotein E (APOE) genotype in early mild cognitive impairment (E-MCI). Front Aging Neurosci. 2013;5:11.

25. Mintun MA, Larossa GN, Sheline YI, Dence CS, Lee SY, Mach $\mathrm{RH}$, et al. [11C]PIB in a nondemented population: potential antecedent marker of Alzheimer disease. Neurology. 2006;67:446-52.

26. Howie BN, Donnelly P, Marchini J. A flexible and accurate genotype imputation method for the next generation of genomewide association studies. PLoS Genet. 2009;5:e1000529.

27. Genomes Project C, Abecasis GR, Altshuler D, Auton A, Brooks LD, Durbin RM, et al. A map of human genome variation from population-scale sequencing. Nature. 2010;467:1061-73.

28. Willer CJ, Li Y, Abecasis GR. METAL: fast and efficient metaanalysis of genomewide association scans. Bioinformatics. 2010;26:2190-1.

29. Kamboh MI, Demirci FY, Wang X, Minster RL, Carrasquillo MM, Pankratz VS, et al. Genome-wide association study of Alzheimer's disease. Transl Psychiatry. 2012;2:e117.

30. Cohen AD, Mowrey W, Weissfeld LA, Aizenstein HJ, McDade E, Mountz JM, et al. Classification of amyloid-positivity in controls: comparison of visual read and quantitative approaches. Neuroimage. 2013;71:207-15.

31. de Leeuw CA, Mooij JM, Heskes T, Posthuma D. MAGMA: generalized gene-set analysis of GWAS data. PLoS Comput Biol. 2015;11:e1004219.

32. Ramanan VK, Risacher SL, Nho K, Kim S, Swaminathan S, Shen L, et al. APOE and BCHE as modulators of cerebral amyloid deposition: a florbetapir PET genome-wide association study. Mol Psychiatry. 2014;19:351-7.

33. Deming Y, Li Z, Kapoor M, Harari O, Del-Aguila JL, Black K, et al. Genome-wide association study identifies four novel loci associated with Alzheimer's endophenotypes and disease modifiers. Acta Neuropathol. 2017;133:839-56.

34. Yu JT, Tan L, Hardy J. Apolipoprotein E in Alzheimer's disease: an update. Annu Rev Neurosci. 2014;37:79-100.

35. Huang YA, Zhou B, Wernig M, Sudhof TC. ApoE2, ApoE3, and ApoE4 differentially stimulate APP transcription and abeta secretion. Cell. 2017;168:427-41 e421.

36. Liu CC, Zhao N, Fu Y, Wang N, Linares C, Tsai CW, et al. ApoE4 accelerates early seeding of amyloid pathology. Neuron. 2017;96:1024-32.

37. Wolf EJ, Rasmusson AM, Mitchell KS, Logue MW, Baldwin CT, Miller MW. A genome-wide association study of clinical symptoms of dissociation in a trauma-exposed sample. Depress Anxiety. 2014;31:352-60.

38. Sung YJ, Perusse L, Sarzynski MA, Fornage M, Sidney S, Sternfeld B, et al. Genome-wide association studies suggest sexspecific loci associated with abdominal and visceral fat. Int J Obes (Lond). 2016;40:662-74.

39. Procopio DO, Saba LM, Walter H, Lesch O, Skala K, Schlaff G, et al. Genetic markers of comorbid depression and alcoholism in women. Alcohol Clin Exp Res. 2013;37:896-904.

40. Batista PJ, Chang HY. Long noncoding RNAs: cellular address codes in development and disease. Cell. 2013;152:1298-307.

41. Luo Q, Chen Y. Long noncoding RNAs and Alzheimer's disease. Clin Interv Aging. 2016;11:867-72.

42. Shi C, Zhang L, Qin C. Long non-coding RNAs in brain development, synaptic biology, and Alzheimer's disease. Brain Res Bull. 2017;132:160-9.

43. Klarin D, Zhu QM, Emdin CA, Chaffin M, Horner S, McMillan $\mathrm{BJ}$, et al. Genetic analysis in UK Biobank links insulin resistance and transendothelial migration pathways to coronary artery disease. Nat Genet. 2017;49:1392-7. 
44. Geering B. Death-associated protein kinase 2: regulator of apoptosis, autophagy and inflammation. Int $\mathrm{J}$ Biochem Cell Biol. 2015;65:151-4.

45. Kim BM, You MH, Chen $\mathrm{CH}$, Suh J, Tanzi RE, Ho Lee T. Inhibition of death-associated protein kinase 1 attenuates the phosphorylation and amyloidogenic processing of amyloid precursor protein. Hum Mol Genet. 2016;25:2498-513.

46. Ruiz A, Heilmann S, Becker T, Hernandez I, Wagner H, Thelen $\mathrm{M}$, et al. Follow-up of loci from the International Genomics of Alzheimer's Disease Project identifies TRIP4 as a novel susceptibility gene. Transl Psychiatry. 2014;4:e358.

47. Flajolet M, He G, Heiman M, Lin A, Nairn AC, Greengard P. Regulation of Alzheimer's disease amyloid-beta formation by casein kinase I. Proc Natl Acad Sci USA. 2007;104:4159-64.

48. Utine GE, Taskiran EZ, Kosukcu C, Karaosmanoglu B, Guleray $\mathrm{N}$, Dogan OA, et al. HERC1 mutations in idiopathic intellectual disability. Eur J Med Genet. 2017;60:279-83.

49. Hashimoto R, Nakazawa T, Tsurusaki Y, Yasuda Y, Nagayasu K, Matsumura $\mathrm{K}$, et al. Whole-exome sequencing and neurite outgrowth analysis in autism spectrum disorder. J Hum Genet. 2016;61:199-206.

50. Xiong X, Zhao Y, Tang F, Wei D, Thomas D, Wang X, et al. Ribosomal protein S27-like is a physiological regulator of p53 that suppresses genomic instability and tumorigenesis. Elife. 2014;3: e02236.

51. Jazvinscak Jembrek M, Slade N, Hof PR, Simic G. The interactions of p53 with tau and Ass as potential therapeutic targets for Alzheimer's disease. Prog Neurobiol. 2018;168:104-127.

52. Chaurasia A, Park SH, Seo JW, Park CK. Immunohistochemical analysis of ATRX, IDH1 and p53 in glioblastoma and their correlations with patient survival. J Korean Med Sci. 2016;31:1208-14.

53. Gambuzza ME, Sofo V, Salmeri FM, Soraci L, Marino S, Bramanti P. Toll-like receptors in Alzheimer's disease: a therapeutic perspective. CNS Neurol Disord Drug Targets. 2014;13:1542-58.

54. Visscher PM, Hemani G, Vinkhuyzen AA, Chen GB, Lee SH, Wray NR, et al. Statistical power to detect genetic (co)variance of complex traits using SNP data in unrelated samples. PLoS Genet. 2014;10:e1004269. 